\title{
As dificuldades encontradas pelos professores no ensino remoto durante a pandemia da COVID-19
}

The difficulties encountered by teachers in remote teaching during the pandemic of COVID-19

Las dificultades de los profesores en la enseñanza a distancia durante la pandemia de COVID-19

Recebido: 13/01/2022 | Revisado: 17/01/2022 | Aceito: 20/01/2022 | Publicado: 22/01/2022

Fabio José Antonio da Silva

ORCID:https://orcid.org/0000-0002-5881-6438

Universidade Estadual de Londrina, Brasil

E-Mail: fjas81@hotmail.com

Ronualdo Marques

ORCID: https://orcid.org/0000-0001-6681-9914

Universidade Federal do Paraná, Brasil

E-mail: ronualdo.marques@gmail.com

Moacir de Souza Júnior

ORCID: https://orcid.org/0000-0002-7612-2034

Instituto Agropolos do Ceará, Brasil

E-mail: msjunior0902@gmail.com

Douglas Grzebieluka

ORCID: https://orcid.org/0000-0002-6097-5411

Secretaria de Estado da Educação do Paraná, Brasil

E-mail: douglasgebeluka@bol.com.br

Jean Carlos Triches

ORCID: https://orcid.org/0000-0002-7127-0193

Faculdade do Oeste de Santa Catarina, Brasil

E-mail: jean.triches@gmail.com

Katiane de Carvalho Lima

ORCID: https://orcid.org/0000-0002-3615-9043 Secretaria de Estado da Educação do Distrito Federal, Brasil E-mail: katiane.lima@gmail.com

José Luis Monteiro da Conceição ORCID: https://orcid.org/0000-0003-3496-8311

Universidade Federal do Sergipe, Brasil E-mail: luisuneb1@hotmail.com

Antônio Igo Barreto Pereira

ORCID: https://orcid.org/0000-0003-2629-3094 Universidade Federal do Acre, Brasil

E-mail: antonio.pereira@ufac.br

José Willen Brasil Lima

ORCID: https://orcid.org/0000-0002-4647-8849 Universidade Federal do Tocantins, Brasil

E-mail: brasilwillen@gmail.com

Eduardo Machado dos Santos

ORCID: https://orcid.org/0000-0002-7936-5672 Instituto Federal de Educação Ciência e Tecnologia de Mato Grosso, Brasil

E-mail: machadoedu@ outlook.com

\begin{abstract}
Resumo
A mudança dos métodos de ensino presencial para o ensino remoto desde o início das medidas de restrições devido a pandemia da COVID-19 exigiu, no campo da educação, a adaptação repentina de educadores, alunos e pais para a garantia da continuidade do ensino e principalmente o ajuste, por parte dos professores, de atividades pedagógicas e estratégias de ensino na promoção da aprendizagem durante a pandemia da COVID-19. Desta forma, o objetivo deste estudo é analisar as dificuldades encontradas pelos professores no ensino remoto durante a pandemia da COVID-19. Nesse processo, educadores, inevitavelmente enfrentaram dificuldades e obstáculos específicos nas instituições, além disso, a infraestrutura tecnológica inadequada de algumas instituições e dificuldades de acesso por parte de muitos alunos, podem ser consideradas outro fator. Esses fatores são um obstáculo para o sucesso do ensino remoto implementado, pois as mudanças ocorridas com o ensino remoto, a aprendizagem online, as dificuldades encontradas podem refletir no ensino presencial, exigindo de professores e alunos uma adaptação mais significativa em novas ou incomuns práticas de ensino para professores e alunos que, tomadas em conjunto, indicam alguma renovação da educação durante e após a pandemia.
\end{abstract}

Palavras-chave: Dificuldades e desafios; Ensino remoto; Pandemia. 


\begin{abstract}
The change from face-to-face teaching methods to remote teaching since the beginning of the restriction measures due to the COVID-19 pandemic required, in the field of education, the sudden adaptation of educators, students and parents for the assurance of teaching continuity and mainly the adjustment, by teachers, of pedagogical activities and teaching strategies in the promotion of learning during the COVID-19 pandemic. Thus, the aim of this study is to analyze the difficulties encountered by teachers in remote teaching during the COVID-19 pandemic. In this process, educators, inevitably faced specific difficulties and obstacles in the institutions, in addition, inadequate technological infrastructure of some institutions and difficulties of access by many students, can be considered another factor. These factors are an obstacle to the success of the implemented remote teaching, because the changes occurred with remote teaching, online learning, the difficulties encountered may reflect in face-to-face teaching, requiring from teachers and students a more significant adaptation in new or unusual teaching practices for teachers and students that, taken together, indicate some renewal of education during and after the pandemic.
\end{abstract}

Keywords: Difficulties and challenges; Remote teaching; Pandemic.

\title{
Resumen
}

El cambio de los métodos de enseñanza presencial a la enseñanza a distancia desde el inicio de las medidas de restricción debido a la pandemia de COVID-19 requirió, en el ámbito de la educación, la adaptación repentina de educadores, alumnos y padres para el aseguramiento de la continuidad de la enseñanza y, principalmente, el ajuste, por parte de los profesores, de las actividades pedagógicas y las estrategias de enseñanza en la promoción del aprendizaje durante la pandemia de COVID-19. Así, el objetivo de este estudio es analizar las dificultades que encuentran los profesores en la enseñanza a distancia durante la pandemia de COVID-19. En este proceso, los educadores, inevitablemente se enfrentaron a dificultades y obstáculos específicos en las instituciones, además, la inadecuada infraestructura tecnológica de algunas instituciones y las dificultades de acceso por parte de muchos estudiantes, puede considerarse otro factor. Estos factores son un obstáculo para el éxito de la enseñanza a distancia implementada, ya que los cambios ocurridos con la enseñanza a distancia, el aprendizaje en línea, las dificultades encontradas pueden reflejarse en la enseñanza presencial, requiriendo de los profesores y estudiantes una adaptación más significativa en las prácticas de enseñanza nuevas o inusuales para los profesores y estudiantes que, en conjunto, indican una cierta renovación de la educación durante y después de la pandemia.

Palabras clave: Dificultades y retos; Enseñanza a distancia; Pandemia.

\section{Introdução}

Mesmo antes do COVID-19, já havia alto crescimento e adoção de tecnologias educacionais, seja em aplicativos de idiomas, aulas virtuais, ferramentas de videoconferência ou software de aprendizagem online, houve um aumento significativo no uso desde COVID-19.

O cenário mundial da rápida disseminação do novo coronavírus (SARS-CoV-2, causador do COVID-19) tem impactado significativamente e direto na economia e a saúde E geram um efeito cascata em uma série de atividades humanas frente às respostas de isolamento e distanciamento sociais praticado pelos diferentes países (Marques \& Fraguas, 2020, p. 86161). Com o objetivo de diminuir a rápida propagação do vírus e preservar a capacidade de funcionamento dos sistemas de saúde, medidas restritivas como o isolamento social têm sido adotadas em diversos países.

No Brasil, a patologia vem se espalhando por todas as regiões. Apesar das orientações da Organização Mundial da Saúde (OMS), o país tem se colocado em uma posição delicada no combate a maior crise sanitária da atualidade devido às dificuldades na aplicação das medidas protetivas recomendadas.

O objetivo deste estudo é analisar as dificuldades encontradas pelos professores no ensino remoto durante a pandemia da COVID-19. O sistema público de saúde do Brasil, o Sistema Único de Saúde (SUS) e o sistema de saúde suplementar, assim como a economia do país, vêm sofrendo os ataques sistemáticos devido aos impactos negativos da pandemia.

A pandemia da SARS-CoV-2 (COVID-19) também trouxe à tona o sucateamento dos hospitais entre outros serviços públicos bem como a precarização desses serviços, e além disso, nesse período observa-se os entraves ao acesso à saúde já conhecidos por uma parcela da população brasileira e consequentemente mudou a educação em todo o mundo.

Nesse contexto de crise sanitária instaurado pelo avanço da pandemia observou-se as mudanças que ocorreram rapidamente afetando diversas atividades, na educação a adaptação das aulas via processo de virtualização de emergência na 
educação frente ao atual contexto da pandemia causada pelo novo coronavírus em que levaram o Estado e as Universidades a adotarem metodologias alternativas, até então, não adotadas em seus ambientes de ensino (Marques et al., 2021, p. 2).

Tais demandas desafiam os professores, estudantes e família, pois introduzem mudanças não somente em suas rotinas profissionais, mas também em seus cotidianos pessoais. Essa emergência fez urgir a necessidade de inovação perante o ato de lecionar, buscar alternativas inovadoras para a mediação do conhecimento com os estudantes (Marques, 2021, p. 7).

Mesmo que o foco seja agora em medidas de emergência, é importante começar a projetar ações pós-pandêmicas para mitigar potenciais dificuldades entre os grupos sociais mais vulneráveis e de aprendizagem na qual ser evidenciou as desigualdades decorrentes do confinamento/isolamento social.

É importante estabelecer estratégias para reabertura de escolas levando em considerar áreas de maior ou menor risco e criar protocolos para limpar as instalações da escola antes do início das aulas. Nos termos educacionais, é importante estabelecer formas de ajudar alunos que tiveram pior acesso à educação a distância ofertada no ensino remoto e avaliar quais práticas de ensino à distância no processo de virtualização de emergência podem ser seguidas com vantagens com a estrutura que foi colocada, estruturada e implementada durante a pandemia.

Também é importante estabelecer ações centralizadas para grupos de risco, como jovens com alto risco de abandono escolar e famílias em alta vulnerabilidade social, além de apoiar famílias de baixa renda para reduzir o choque econômico da pandemia, que também afeta o retorno das crianças à escola.

Quando se discute a educação, em um sistema-mundo globalizado e com tal velocidade, são notórias as discussões para criar diálogo entre os alunos, que vivem essa velocidade com a prática de ensino-aprendizagem, normalmente tradicional. O fenômeno contemporâneo que se verifica são as estratégias educativas que utilizam as tecnologias como ferramenta. A utilização das Tecnologias de Informação e Comunicação (TICs) possuem como objetivo fazer o aluno compreender os conteúdos de forma mais intuitiva. O processo de ensino-aprendizagem sendo mais intuitivo torna-se também mais fluido e mais palpável à realidade do aluno, a visualização do processo. Estes recursos (TICs) em sala de aula são de extrema importância e ajuda principalmente nas disciplinas e conteúdos que exigem do aluno maior imaginação. É preciso considerar, antes de tudo, "o importante papel que cumprem as políticas públicas neste momento de crise e novos arranjos das estruturas escolares" (Marques et al., 2021, p. 781).

\section{Metodologia}

Partindo desses pressupostos iniciais, esse estudo se configura metodologicamente como uma pesquisa qualitativa bibliográfica, elaborada a partir da análise e interpretação do conteúdo realizada em artigos, livros, teses e dissertações e textos da internet, levando ao pesquisador buscar ideias relevantes ao estudo, com registro confiável de fontes. Segundo Denzin e Lincoln (2006), a pesquisa qualitativa envolve uma abordagem interpretativa do mundo o que implica numa ênfase sobre as qualidades das entidades, dos processos e significados, o que determina que seus pesquisadores estudem as coisas em seus cenários naturais, tentando entender os fenômenos em termos dos significados que as pessoas a eles conferem, evidenciando também as limitações situacionais que influenciam a investigação.

Nesse contínuo, Gunther (2006), apresentam quatro bases teóricas da pesquisa qualitativa,

a) a realidade social é vista como construção e atribuição social de significados; b) a ênfase no caráter processual e na reflexão; c) as condições "objetivas"de vida tornam-se relevantes por meio de significados subjetivos; d) o caráter comunicativo da realidade social permite que o refazer do processo de construção das realidades sociais torne-se ponto de partida da pesquisa (Gunther, 2006, p. 202).

No primeiro momento buscamos desvelar elementos do ensino remoto e ensino híbrido, e diante desse contexto do 
processo de virtualização de emergência discorrer sobre os desafios da educação básica na pandemia, bem como as possibilidades para a educação básica no ensino remoto.

\section{Ensino Remoto e Ensino Híbrido}

Embora os ambientes da escola e da sala de aula sejam lugares importantes para os alunos terem experiências sociais, as casas das crianças se tornaram o novo ambiente educacional, sem interações sociais físicas com seus professores e colegas (Médici et al., 2020).

$\mathrm{O}$ isolamento social e a falta de interatividade têm sido considerados como uma grande deficiência do ensino remoto de emergência, já que a tecnologia se tornou o único canal das crianças para interagir com professores e colegas.

Durante o ensino a distância emergencial, os pais podem ser considerados um dos mais importantes atores da educação a distância diante do contexto da pandemia, pois são os únicos que acompanham fisicamente seus filhos. Desde que os lares das crianças se tornaram o novo ambiente de aprendizagem durante a pandemia, os pais influenciam a aprendizagem de seus filhos, fornecendo tecnologias digitais, ambiente de aprendizagem e aprendendo como apoiar seus filhos (ROSA, 2020)

Esta nova situação colocou uma grande carga sobre os cuidadores e pais. Embora pouca pesquisa tenha sido conduzida para compreender as opiniões dos pais durante este tipo de experiência de aprendizagem, as perspectivas e experiências dos pais de ensino remoto de emergência podem influenciar a qualidade e a quantidade do aprendizado online no futuro (Rosa, 2020)

Quando a pandemia COVID-19 acabar, o sistema educacional não deve se esquecer das experiências que ganhamos durante o ensino à distância de emergência. É provável que surjam circunstâncias semelhantes (desastres) no futuro e espera-se que o fechamento de escolas implemente o ensino à distância de emergência (Machado, 2020).

Assim, é importante agora avaliar nossas experiências para estarmos melhor preparados para as necessidades futuras de realização do ensino a distância de emergência. Em tal situação emergente, o sistema geralmente não leva em consideração os sentimentos dos alunos e pais. No entanto, todas essas mudanças de emergência no sistema educacional têm causado a preocupação dos pais com a educação, a saúde física e mental de seus filhos (Rosa., 2020).

Conforme expressado por Machado (2020), quando as coisas voltarem ao normal, os alunos vão se lembrar de como se sentiram nessa situação, assim como seus pais. Dada a possibilidade de se deparar com situações semelhantes no futuro, as opiniões dos pais são importantes para orientar e contribuir com o processo.

O ensino à distância de emergência requer circunstâncias diferentes das condições usuais, uma vez que não estávamos preparados em termos de infraestrutura técnica, desenvolvimento profissional e conjunto de habilidades (Alves, 2020).

A falta de preparação por parte das escolas, alunos e seus pais é a principal dificuldade na educação a distância realizada durante a pandemia. A interrupção da educação nas escolas tornou a rápida transição para a educação à distância mais importante. Tem trazido vários problemas para os pais, como a falta de infraestrutura e habilidades relacionadas à educação dos filhos (Machado, 2020).

Nessa situação emergente, a maioria dos alunos precisava da orientação de seus pais as tecnologias ampliam as possibilidades de pesquisa online, de trazer materiais importantes e atualizados para o grupo, de comunicar-nos com outros professores, alunos e pessoas interessantes, de ser coautores, "remixadores" de conteúdos e de difundir nossos projetos e atividades, individuais, grupais e institucionais muito além das fronteiras físicas do prédio (Moran, 2015, p.19).

Os potenciais efeitos educacionais, econômicos, sociais e de saúde de um longo período sem precedentes fechamento de escolas devido à pandemia de coronavírus são analisados por muitos pesquisadores de diferentes disciplines.

Os estudos empíricos são baseados em dados muito escassos coletados em alguns países durante e após os períodos de 
encerramento de escolas e, principalmente, em descobertas anteriores sobre interrupções escolares durante as férias ou eventos inesperados. Vários estudos descobriram que as férias de verão são seguidas por perdas cognitivas consideráveis e significativas, que muitas vezes dizem respeito mais à matemática do que à leitura, e tendem a ser maiores para alunos de nível socioeconômico inferior (Rosa, 2020).

É compreensível que a mudança para um ambiente de aprendizagem em casa e ter um pai como um professor impacta a motivação. Além das regras domésticas típicas, as estruturas de aprendizagem necessárias para ser estabelecida, e a cooperação nesta nova tarefa pode ser incansável. Uma quantidade maior de distrações não baseadas na educação existe na maioria das casas. Ganhar a cooperação dos alunos para tarefas além tarefas típicas podem levar a mais negociações (Médici et al., 2020).

O aprendizado à distância de acordo com Machado (2020) só será motivador e envolvente se as preferências do aluno confortarem níveis e estilos de aprendizagem são levados em consideração, assim como as melhores práticas fazem na sala de aula física.

Educadores e os formuladores de políticas devem organizar alguns programas de treinamento em aprendizagem remota eficaz em casa para pais considerando suas lutas indicadas neste estudo (Castells, 2010).

Os esforços para fornecer recursos e ferramentas de apoio aos pais foram predominantemente reacionários. Educar os pais sobre o sistema e as plataformas de aprendizagem remota, incluindo as ferramentas, principais conceitos pedagógicos e opções de comunicação professor-aluno-pais, é essencial para futuros esforços de aprendizagem remota.

\subsection{Desafios da educação básica na pandemia}

A escola é o lugar da convivência. Os espaços e práticas escolares sempre foram pensados para favorecer a interação e o aprendizado a partir da experiência concreta. A aula pratica que se realizam ao longo do ano letivo, como aulas passeios, arte, a dança, a música. Tudo isso foram impactos causados pela pandemia.

O professor como educador deve adotar em sala de aula é uma medida necessária para atender os anseios dos alunos.

[...] com relação à atividade escolar, é interessante destacar que a interação entre alunos também provoca intervenções no desenvolvimento das crianças. Os grupos de crianças são sempre heterogêneos quanto ao conhecimento já adquirido nas diversas áreas e uma criança mais avançada num determinado assunto pode contribuir para o desenvolvimento de outras. Assim como o adulto, uma criança também pode funcionar como mediadora entre uma criança, ações e significados estabelecidos como relevantes no interior da cultura. (Oliveira, 2001, p.45).

A escola é para todos os alunos e não apenas para os bem sucedidos, pois a nossa responsabilidade é determinante na aprendizagem e motivação do aluno.

De acordo com Nóvoa (2000), os professores passam por dois estágios no início da carreira: a "sobrevivência" e a "descoberta". O primeiro, diz respeito ao confronto com a realidade, até então obscura.

O professor já não pode ser mais o que professa o saber, o conhecedor de todas as coisas, o que ilumina o aluno "sem luz", sem o saber, dependente do seu mestre para ser educado. Surge então a imagem do facilitador, o gerenciador de ideias, o dinamizador da inteligência coletiva, o que problematiza e questiona e não traz mais as respostas, como antes feito pelo professor. Sua função não é mais a de saber todas as coisas e trazer todas as respostas prontas. Realidade de um pequeno e elitizado grupo social. (Freitas, 2000)

O Brasil está enfrentando esta situação inédita em uma área que tradicionalmente não tem uma cultura de digital, trabalho a distância ou educação a distância. Isso é novo e complexo para quem trabalha com educação básica em escolas públicas e privadas (Kenski, 2012).

Agora, observamos que muitas pessoas começaram a perceber que há ganhos e não apenas perdas neste período, e a 
aceitação se tornou mais comum. Muitos professores e alunos começaram a falar sobre os aspectos positivos da pandemia COVID-19: voluntariado, mentoria, serviço à comunidade, altruísmo, construção de identidade profissional, definição do que é realmente importante nos objetivos e conteúdo do programa médico e educação profissional (Machado, 2020).

$\mathrm{O}$ estado emocional do professor interfere em suas atividades de ensino e aprendizagem dos alunos e sua motivação para aprender e aplicar novas tecnologias ou para resistir a qualquer inovação. As escolas devem fornecer suporte emocional e pedagógico aos seus docentes e alunos, considerando os desafios do COVID-19 (Médici et al., 2020).

O fechamento de escolas causou alguns problemas em relação à aprendizagem remota em casa entre os pais, embora os pais apoiassem a política de fechamento da escola. Este estudo preliminar destacou a necessidade de examinar as preocupações dos pais sobre aprendizagem remota (Rosa, 2020).

Precisamos equipar pais com estratégias eficazes para cuidar e proteger o futuro do mundo. Pesquise e discussões considerando as vozes dos pais sobre o impacto de uma pandemia ajudariam os educadores e formuladores de políticas com planejamento acadêmico futuro. (Souza et al., 2016).

\subsection{Possibilidades para a educação básica no ensino remoto}

A escola é o lugar da convivência. Os espaços e práticas escolares sempre foram pensados para favorecer a interação e o aprendizado a partir da experiência concreta. A aula pratica que se realizam ao longo do ano letivo, como aulas passeios, arte, a dança, a música. Tudo isso foram impactos causados pela pandemia. Qualquer aprendizagem que aconteça fora da sala de aula, sem o professor presente no mesmo local dos alunos. Isso inclui soluções remotas digitais e não digitais.

$\mathrm{O}$ aprendizado remoto fornecido por meio de tecnologias digitais, geralmente conhecido como aprendizado online. Uma mistura de métodos presenciais e remotos. Um exemplo seria a 'sala de aula invertida', onde a entrada principal acontece remotamente (por exemplo, por meio de vídeo), enquanto a prática e a tutoria acontecem em sala de aula (Rosa, 2020).

A chamada educação síncrona, isto é, ao vivo, normalmente uma aula ao vivo, mas também reflete outras práticas ao vivo, como grupos de bate-papo, tutoriais e discussões individuais que também acontecem em um ambiente online ao vivo. A educação assíncrona é quando o professor prepara o material e o aluno acessa posteriormente (Alves, 2020).

É provável que a pandemia COVID-19 também tenha um efeito duradouro no planejamento das aulas. As limitações da pandemia forneceram uma oportunidade para os educadores considerarem novas estratégias para ensinar conceitos direcionados. Embora repensar as abordagens instrucionais tenha sido forçado e apressado, a experiência serviu como uma rara chance de reconsiderar as estratégias que melhor facilitam o aprendizado dentro das possibilidades e restrições do contexto online (Joye et al; 2020),

Alves (2020) cita que embora a indefinição das linhas entre a educação tradicional e a distância tenha sido observada por várias décadas, a pandemia avançou rapidamente no apagamento dessas fronteiras. Menos modo único, mais multimodo (e, portanto, mais opções do educador) está se tornando a norma devido à infraestrutura aprimorada e conjuntos de habilidades desenvolvidos que permitem que as pessoas se movimentem em diferentes sistemas de distribuição.

As práticas recomendadas bem estabelecidas de ensino e aprendizagem híbridos ou combinados serviram como um guia para novas combinações de entrega instrucional que se desenvolveram em resposta à mudança para a aprendizagem virtual (Alves, 2020).

O uso de vários modos de entrega provavelmente permanecerá e será um recurso empregado por alunos de todas as idades. As iterações futuras da educação online não estarão mais presas às tradições de modos de ensino únicos, pois os educadores podem apoiar abordagens pedagógicas a partir de um menu de opções de ensino, uma combinação que foi apoiada por gerações anteriores de educadores online. A interação é importante para a aprendizagem, mas interações forçadas entre os alunos por uma questão de interação não são motivadoras nem benéficas. (Joye et al., 2020). 
Também são significativas as mudanças em como os resultados da aprendizagem são determinados em ambientes online. Muitos educadores alteraram a forma como o desempenho dos alunos é medido, eliminando atribuições e mudando completamente as estratégias de avaliação (Rosa, 2020).

Essas alterações incluem determinar a aprendizagem por meio de estratégias que potencializam o modo de entrega online, como discussões interativas, ensino liderado por alunos e o uso de jogos para aumentar a motivação e atenção.

Mudanças específicas que provavelmente continuarão incluem prazos flexíveis ou estendidos para a conclusão de tarefas, mais escolha do aluno em relação às medidas de aprendizagem e experiências mais autênticas que envolvem a aplicação significativa de habilidades e conhecimentos recém-aprendidos, por exemplo, projetos baseados em equipe que envolvem múltiplos ferramentas criativas e de mídia social para apoiar a resolução colaborativa de problemas (Lopes 2016, p. 31).

Antes da pandemia, o objetivo principal da educação à distância e online era fornecer acesso à instrução para aqueles que, de outra forma, não poderiam participar de um programa acadêmico tradicional local. Como seu objetivo mudou para apoiar a continuidade da instrução, seu público, bem como o ecossistema de aprendizagem mais amplo, mudou. Será interessante ver quais aspectos do ensino à distância de emergência permanecem na próxima geração de educação, quando a ameaça do COVID-19 não for mais um fator. Mas a educação online sem dúvida encontrará novos públicos (Rosa, 2020).

A flexibilidade e as possibilidades de aprendizagem que surgiram da necessidade provavelmente mudarão as expectativas dos alunos e educadores, diminuindo ainda mais a linha entre a instrução em sala de aula e a aprendizagem virtual (Machado, 2020).

O professor já não pode ser mais o que professa o saber, o conhecedor de todas as coisas, o que ilumina o aluno "sem luz", sem o saber, dependente do seu mestre para ser educado. Surge então a imagem do facilitador, o gerenciador de ideias, o dinamizador da inteligência coletiva, o que problematiza e questiona e não traz mais as respostas, como antes feito pelo professor. Sua função não é mais a de saber todas as coisas e trazer todas as respostas prontas. Realidade de um pequeno e elitizado grupo social. (Freitas, 2000)

O acesso desigual a ferramentas digitais, conectividade e falta de treinamento impôs desafios invisíveis para governos, escolas e professores para envolver os alunos em educação à distância durante a pandemia COVID-19.

Essa mudança abrupta afeta todos os atores nos sistemas educacionais, mas os alunos com baixo nível socioeconômico pode ser atingido de forma crítica: os governos estão preocupados com o risco de aprofundar as já grandes lacunas de aprendizagem entre grupos socioeconômicos e com a taxa de evasão.

Para discutir esses desafios, a equipe de Educação do Brasil do Banco Mundial fez parceria com a organização não governamental Todos Pela Educação (TPE) e o Conselho Nacional de Educação para realizar o webinar "Educação Frente a uma Pandemia".

O fechamento de escolas é uma realidade global que afeta mais de $90 \%$ dos alunos em todo o mundo. Alguns países estão usando televisão, rádio e dispositivos móveis para oferecer aulas virtuais. A maioria combina essas estratégias. No entanto, como essa mudança surge tão abruptamente quanto a pandemia COVID, muitos professores ainda não estão familiarizados com o uso da tecnologia para fins pedagógicos e estão aprendendo enquanto tentam ensinar remotamente. Estudar em casa também requer muito envolvimento das famílias dos alunos e isso tem sido um desafio em todos os lugares (Machado, 2020, p.4).

As escolas devem fazer o possível para construir um relacionamento próximo com os alunos e suas famílias, para que possamos garantir que a educação seja um objetivo comum. As escolas também devem oferecer atividades independentemente do seu contexto. É fundamental manter os alunos envolvidos para mitigar as perdas de aprendizagem e o distanciamento das atividades educacionais causadas pela pandemia. 
O Brasil está enfrentando esta situação inédita em uma área que tradicionalmente não tem uma cultura de digital, trabalho a distância ou educação a distância. Isso é novo e complexo para quem trabalha com educação básica em escolas públicas e privadas (Kenski, 2012).

Agora, observamos que muitas pessoas começaram a perceber que há ganhos e não apenas perdas neste período, e a aceitação se tornou mais comum. Muitos professores e alunos começaram a falar sobre os aspectos positivos da pandemia COVID-19: voluntariado, mentoria, serviço à comunidade, altruísmo, construção de identidade profissional, definição do que é realmente importante nos objetivos e conteúdo do programa médico e educação profissional (Machado, 2020).

$\mathrm{O}$ estado emocional do professor interfere em suas atividades de ensino e aprendizagem dos alunos e sua motivação para aprender e aplicar novas tecnologias ou para resistir a qualquer inovação. As escolas devem fornecer suporte emocional e pedagógico aos seus docentes e alunos, considerando os desafios do COVID-19.

Muitos educadores não conhecem adequadamente as crescentes possibilidades tecnológicas do século XXI, sendo imigrantes digitais, enquanto os alunos são nativos digitais. Muitos professores cometeram erros ao tentarem fazer o melhor e os alunos reconheceram seus esforços, mostrando empatia pela dedicação de seus professores (Souza et al., 2016).

Estudantes de medicina ajudaram seus professores, e uma forte colaboração se desenvolveu entre professores e alunos, às vezes mais forte do que antes da pandemia. O número de professores que decidiram participar de atividades de desenvolvimento docente foi maior do que antes.

Porém, quem mudou, se adaptou e tentou fazer algo para manter o processo educacional vislumbrou o futuro, vivenciando uma forma diferente de ensinar e aprender. Professores e alunos que vivenciaram a perda da formação médica tradicional, mesmo que temporária, podem ou não ter vivenciado as fases do luto, mas certamente saíram da experiência mais sábios e resilientes, com novas habilidades.

Para as famílias, e especialmente para as mulheres, que costumam ser as principais responsáveis pelos cuidados com os filhos, o fechamento de escolas pode significar o acúmulo de atividades de home office e creches. Mas, mesmo para aqueles capazes de encontrar alternativas durante a pandemia, é importante observar que o apoio dos pais aos trabalhos escolares dos filhos está fortemente correlacionado com o status socioeconômico. Por essas razões, é fundamental apoiar o envolvimento dos pais na educação da criança durante as pandemias Covid-19 - especialmente quando o foco é mitigar as desigualdades de aprendizagem (Machado, 2020).

Para entender melhor como os alunos são vulneráveis ao fechamento de escolas, uma alternativa é combinar em um índice a disponibilidade de merenda escolar; o uso da tecnologia em sala de aula; Apoio da família; se o aluno trabalha fora de casa; seu desempenho em testes padronizados e a probabilidade de abandono escolar. Os alunos de baixo desempenho que desistiram no passado são mais vulneráveis às pandemias quando as refeições escolares são cortadas, os professores não estão preparados para o ensino remoto e as famílias estão menos engajadas em ensino doméstico, do que os alunos na situação oposta.

\section{Considerações Finais}

O ensino deve basear-se em concepções que priorizem o trabalho ativo dos discentes frente aos problemas reais da sociedade, onde haja uma reconciliação entre teoria e prática.

Apesar de todas as mudanças e conquistas no campo da educação, determinadas dificuldades permeiam a realidade de professores ao ensino de suas disciplinas exigindo uma dedicação mais significativa como forma de despertar o interesse dos alunos a esta disciplina importante no contexto educacional, principalmente no período do ensino remoto, que exige muito mais de educadores, pais e alunos.

O processo de ensino à distância que entrou em nossas vidas com o COVID-19 pode ser considerado uma nova 
plataforma para alunos, pais, professores e escolas.

Um dos problemas que os alunos encontraram foi o problema de comunicação causado por não serem capazes de compartilhar o mesmo ambiente físico com seus colegas e professores. Assim, em tal ambiente online, os esforços dos professores seriam particularmente importantes em termos de manter contato com os alunos e apoiar a comunicação entre eles.

É especialmente importante não perceber o processo de educação a distância como acadêmico para as crianças mais novas (nível pré-escolar) e lembrar que as necessidades básicas das crianças neste período são as brincadeiras livres e atividades ao ar livre. Por esse motivo, se os professores comunicam que também vivenciam sentimentos e necessidades semelhantes, como manter contato com seus alunos, sentir saudades de amigos e professores, isso ajudaria as crianças mais novas a superar a situação com mais facilidade.

Em uma aula presencial, a comunicação e a interação fora dos círculos acadêmicos tornam-se simultaneamente parte do processo de ensino e aprendizagem. No entanto, quando as aulas online são projetadas principalmente para transmitir conhecimento acadêmico, os alunos ficam entediados facilmente.

Por esse motivo, é importante planejar cuidadosamente as experiências de aprendizagem online para que os alunos passem um tempo eficiente durante as aulas online. Isso pode ser feito orientando os alunos a serem ativos fora das sessões ao vivo, com perguntas interessantes e várias atribuições de projeto. Ensinar dessa forma não só atrairá a atenção das crianças, mas também motivará os alunos a se responsabilizarem por sua aprendizagem e, consequentemente, pela construção do conhecimento.

Um elemento chave é o acesso a infraestrutura e equipamentos digitais de boa qualidade, incluindo ferramentas e competência para garantir a segurança digital durante o aprendizado online.

Fomentar o desenvolvimento de um ecossistema de educação digital de alto desempenho e melhorar as aptidões e competências digitais para a transformação digital.

O ensino à distância de emergência que entrou em nossas vidas com a pandemia COVID-19 proporcionou uma compreensão do papel da escola fora da educação. Demonstrou que a escola não é apenas um local de aprendizagem, mas também um espaço social comum que proporciona socialização, cuidado, facilitação e coaching. Além disso, também revelou que a tecnologia é inevitável e que a educação a distância pode se tornar uma parte importante de nossas vidas no futuro.

\section{Referências}

Alves, L. (2020). Educação remota: entre a ilusão e a realidade. Interfaces Científicas Educação, 8(3), 348-65

Castells, M. (2010). A sociedade em rede. Ed. Paz e Terra, 2010.

Denzin, N, Lincoln, Y. (2006). Introdução: a disciplina e a prática da pesquisa qualitativa. In: Denzin, Normam, Lincoln, Yonna. (Orgs.). O planejamento da pesquisa qualitativa: teorias e abordagens. (2a ed.), Artmed, 15-41.

Freitas, H. C. L. (2000). O Trabalho como princípio articulador da Teoria/Prática: uma análise da prática de ensino e estágio supervisionados na habilitação magistério do curso de Pedagogia da FE/Unicamp. Universidade Estadual de Campinas, Faculdade de Educação.

Gunther, H. (2006). Pesquisa qualitativa versus pesquisa quantitativa: esta é a questão? Psic.: Teor. e Pesq., 22 (2), $201-209$.

Joye, C., Moreira, M., \& Rocha, S. (2020). Educação a Distância ou Atividade Remota Emergencial: em busca pelo elo perdido da educação escolar em tempos de COVID-19. Research, Society and Development, 9 (7), e521974299.

Kenski, V. M. (2012). Educação e tecnologias: o novo ritmo da informação. Editora Papirus, 141.

Lopes, C. G. (2016). Aprendizagem colaborativa e o ensino de História na palma da mão: o WhatsApp como ferramenta de ensino aprendizagem. (Mestrado profissional em Ensino de História) - Universidade Federal do Tocantins, Araguaína.

Machado, P. L. P. (2020). Educação em tempos de pandemia: O ensinar através de tecnologias e mídias digitais. Revista Científica Multidisciplinar Núcleo do Conhecimento, $8(6), 58-68$.

Marques, R., Fraguas, T., \& Campos, M. A. T. (2021). Os professores frente ao trabalho remoto: a Covid-19 como determinante para uma "virtualização de emergência". Debates Em Educação, 13(31), 778-799. 
Research, Society and Development, v. 11, n. 2, e17511225709, 2022

(CC BY 4.0) | ISSN 2525-3409 | DOI: http://dx.doi.org/10.33448/rsd-v11i2.25709

Marques, R. (2021). O professor em trabalho remoto no contexto da pandemia da COVID-19. Boletim De Conjuntura (BOCA), 6(16), 06-14. https://doi.org/10.5281/zenodo.4642898

Marques, R., Sammarco, Y. M., Peixoto, K. H., Litaiff, P. B., Jessen, L. F., Pedroso, P. A. R., Silva, B. G. da, Costa, J., Silva, L. A. da, Agnol, L. D., Araújo, G. C. N. de, \& Inácio Junior, J. (2021). Interfaces do PIBID na formação inicial e na práxis pedagógica num trabalho colaborativo para a construção da identidade profissional. Research, Society and Development, 10(10), e118101018534.

Marques, R., \& Fraguas, T. (2020). A Ressignificação da Educação: virtualização de emergência no contexto de pandemia da COVID-19. Brazilian Journal of Development, 6(11), 86159-86174.

Médici, M. S., Tatto, E. R., \& Leão, M. F. (2020). Percepç̃̃es de estudantes do Ensino Médio das redes pública e privada sobre atividades remotas ofertadas em tempos de pandemia do coronavírus. Revista Thema, 18, 136-155.

Moran, E. (2015). A Cabeça bem feita: repensar a reforma, reformar o pensamento. Trad.: Eloá Jacobina. (6a ed.), Bertrand Brasil.

Nóvoa, A. (2000). Os professores e sua formação. Dom Quixote.

Oliveira, V. F (2001). A formação de professores revista os repertórios guardados na memória. In: Oliveira, Valeska F. de. (org.). Imagens de Professor: significações do trabalho docente. Ijuí, UNIJUí.

Rosa, R. T. N. (2020). Das aulas presenciais às aulas remotas: as abruptas mudanças impulsionadas na docência pela ação do Coronavírus - o COVID-19!. Rev. Cient. Schola Colégio Militar de Santa Maria Santa Maria, Rio Grande do Sul, Brasil. VI, $\mathrm{n}^{\circ} 1$.

Souza, S., Franco, V. S., \& Costa, M. L. F. (2016). Educação a distância na ótica discente. Educação e Pesquisa, 42(1), 99-114.

Vygotsky, L. S. (1991). A formação social da mente. Martins Fontes. 